\title{
Effect of acute administration of propranolol on ventricular function in hypertrophic obstructive cardiomyopathy measured by non-invasive techniques ${ }^{1}$
}

\author{
C. Saenz de la Calzada, ${ }^{2}$ G. M. Ziady, T. Hardarson, R. Curiel, and J. F. Goodwin \\ From the Division of Cardiovascular Diseases (Clinical Cardiology), Department of Medicine, Royal \\ Postgraduate Medical School, and Hammersmith Hospital, London
}

Seventeen patients with hypertrophic obstructive cardiomyopathy, were studied using non-invasive techniques before and after the intravenous injection of $5 \mathrm{mg}$ propranolol. The following were analysed: left ventricular ejection time index, derived from the carotid pulse and heart rate; the isovolumic relaxation time, derived from the apex cardiogram and phonocardiogram; the diastolic closure rate of the mitral valve; and left ventricular diameters, systolic and diastolic, both measured by echocardiography.

Propranolol produced shortening of the isovolumic relaxation time, increase in both the diastolic closure rate of the mitral valve and left ventricular systolic and left ventricular diastolic diameters. These results show that propranolol increases the rate of filling and the volume of the left ventricle, indicating that an improvement in distensibility is produced by beta-adrenergic blockade.

Since the first description of hypertrophic obstructive cardiomyopathy (HOCM) or idiopathic hypertrophic subaortic stenosis (Brock, 1957; Braunwald et al., 1960; Goodwin et al, 1960), advances have been made in the treatment of this disease, both medically and surgically (Flamm, Harrison, and Harcock, 1968; Bentall et al., 1965; Cooley et al., 1967).

The acute effects of beta-adrenergic blockade with propranolol in HOCM suggest that it produces an improvement in distensibility and filling of the left ventricle (Webb-Peploe et al., 1971). Propranolol has been thought to be the treatment of choice (Hubner et al., 1973).

Because most drug studies involve using invasive techniques, they are not applicable for the repeated assessment of patients, and therefore the beneficial effects of propranolol in HOCM must be judged mainly by symptomatic assessment of the patient (Cohen and Braunwald, 1967; Hubner et al., 1973).

The purpose of the present paper is to study the acute effect of propranolol ( $5 \mathrm{mg}$ intravenously) in

Received 19 December 1975.

1This paper was presented at the VII World Congress of Cardiology, 1-7 September 1974, Buenos Aires, Argentina. 2Present address: Division of Cardiology, C. S. ' 1 ' de Octubre', Madrid, Spain.
HOCM, using simple bedside non-invasive techniques, and see if these methods are sensitive enough to detect the haemodynamic benefit of beta-blockade.

\section{Subjects and methods}

The present series consists of 17 adult patients with HOCM. Eleven were women and six men. The diagnosis was proven by previous catheterization and angiocardiography.

All patients stopped propranolol therapy 4 to 7 days before the investigation, which was carried out in the early afternoon with the patient lying supine.

\section{Non-invasive studies}

These were recorded using a 6-channel Cambridge Machine (model 72112, Cambridge Scientific Instruments, England), at a paper speed of $100 \mathrm{~mm}$ per second. The sensitivity settings of the control study were used in the post-propranolol state. The following studies were made.

(1) Electrocardiogram A bipolar lead showing clearly the beginning of the QRS complex was recorded simultaneously with the rest of the tracing.

(2) Phonocardiogram A clear aortic component 


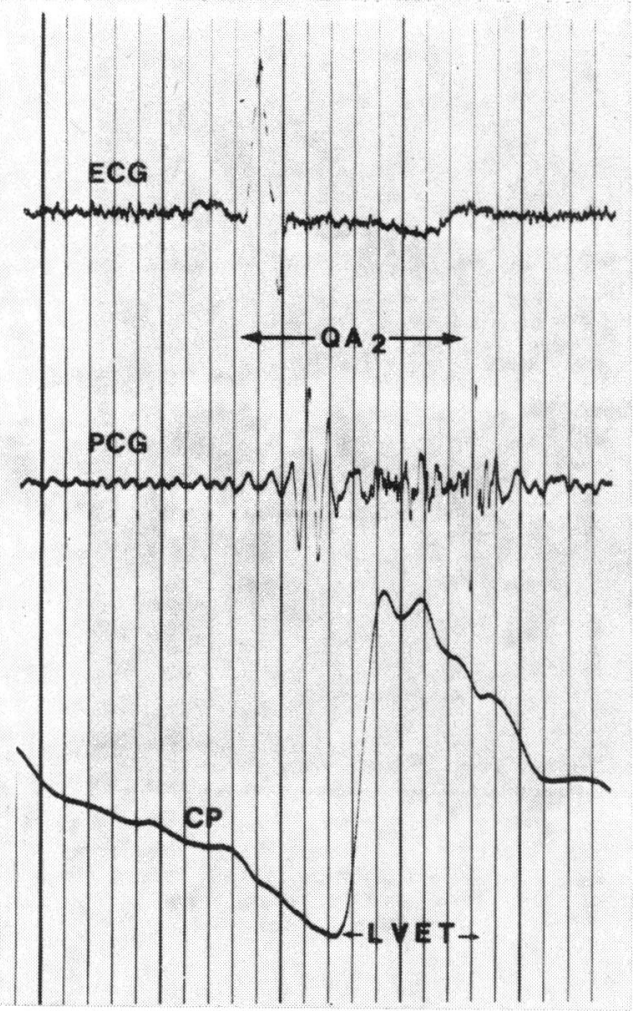

of the second heart sound was obtained. Phonocardiograms were recorded at the third and fourth intercostal spaces along the left sternal border using suction microphones with high (band with 450 and $1.000 \mathrm{~Hz}$ ) frequency filters.

(3) Carotid pulse A clear upstroke and dicrotic notch was obtained.

(4) Apex cardiogram A well-inscribed ' $O$ ' point was obtained. Recordings were made with the patient in the left anterior oblique position.

Carotid and apex cardiogram tracings were obtained with a hand-held polythene funnel connected to a piezoelectric transducer with a pulse amplifier of time constant $1.6 \mathrm{~s}$, band with 0.1 to $100 \mathrm{~Hz}$.

(5) Echocardiography (12 patients only). Echocardiograms were made using an Ekolone 20 diagnostic ultrasound (frequency $2 \cdot 25 \mathrm{MHz}$, repetition frequency $1000 / \mathrm{s}$ ), with polaroid photography.

The following measurements were analysed:

(A) Left ventricular ejection time index (LVETI), taken as the time (in ms), from the carotid upstroke to the dicrotic notch (LVET). The values were

FIG. 1 Simultaneous tracing of the electrocardiogram (ECG), phonocardiogram (PCG), and carotid pulse $(C P)$, illustrating the measurement of left ventricular ejection time (LVET).

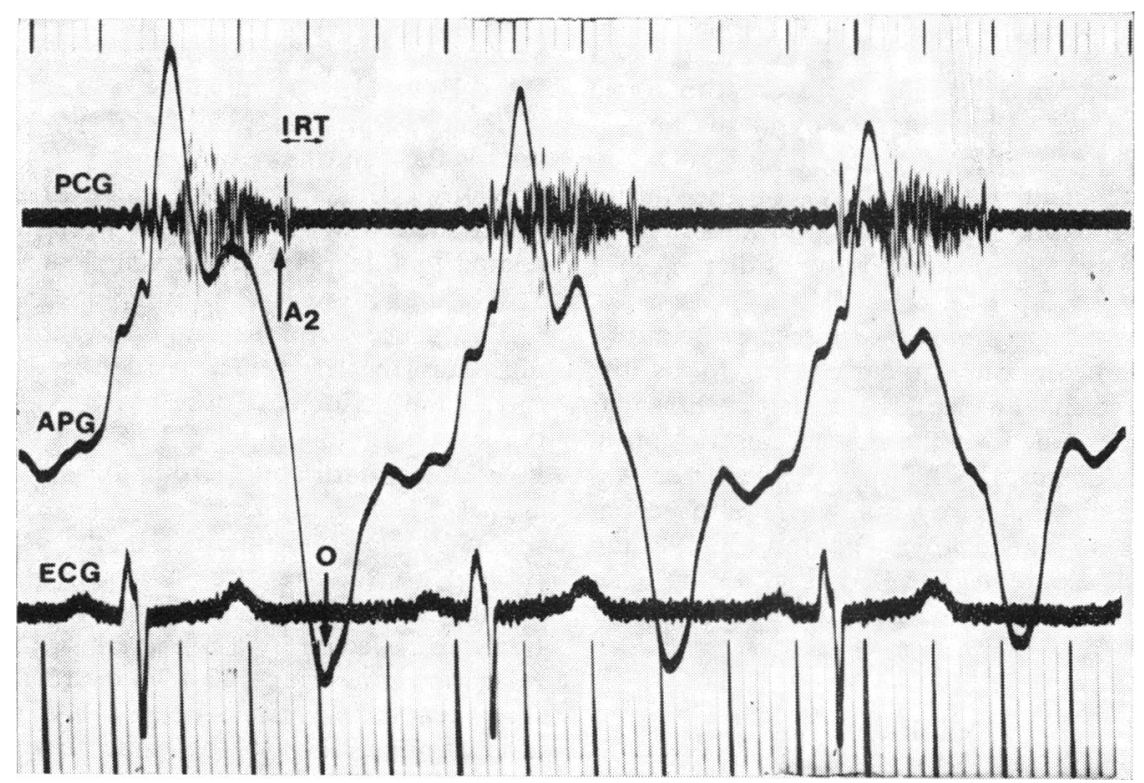

FIG. 2 Simultaneous tracing of the electrocardiogram (ECG), phonocardiogram (PCG), and apex cardiogram (APG), illustrating the measurement of isometric relaxation time (IRT). 


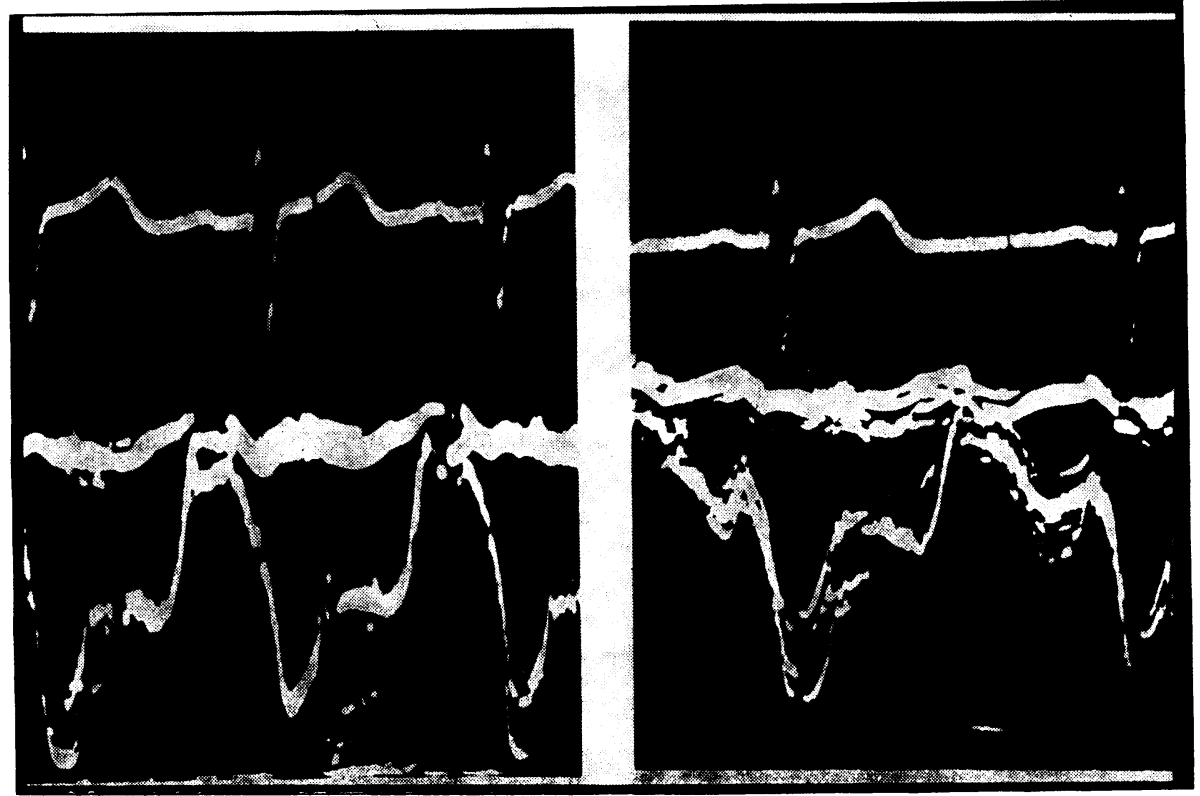

FIG. 3 Mitral echogram before and after propranolol.

corrected for heart rate (LVETI), using the regression equation of Weissler, Harris, and Schoenfeld (1968) (Fig. 1).

(B) Isometric relaxation time (IRT) was expressed in $\mathrm{ms}$, and measured as the time from the aortic component of the second heart sound to the ' $\mathrm{O}$ ' point of the apex cardiogram (Fig. 2).

(C) Diastolic closure rate (DCR) of the mitral echogram was expressed in $\mathrm{mm} / \mathrm{s}$ and measured in the usual way, as described by Edler (1967) (Fig. 3).

(D) Left ventricular diameters by echocardiography Diastolic diameter was measured in $\mathrm{cm}$ as the distance between the septal and left ventricular echoes at the moment of the $R$ wave inscription of the electrocardiogram. The systolic diameter was measured in the same way but when both echoes were closest to each other (Pombo. Troy, and Russell, 1971; Popp et al., 1973) (Fig. 4).

(E) Heart rate This was measured in beats per minute.

\section{Results}

The results of the present study are summarized in the Table. After propranolol, heart rate decreased from $79 \pm 18$ beats per minute in the control state to
$67 \pm 9$. This change is statistically significant $(\mathbf{P}<0.005)$.

Left ventricular ejection time index (LVETI) became shorter after the drug administration (from $428 \pm 33$ to $419 \pm 37 \mathrm{~ms})(P<0 \cdot 05)$.

Because all patients in the present study had left ventricular outflow obstruction as shown by previous catheter data not included in the paper, the reduction of LVETI after propranolol may be related to a decrease in left ventricular obstruction, a well-known effect of propranolol in this disease.

The acute administration of $5 \mathrm{mg}$ propranolol did dilate the left ventricle as judged by the echocardiographic increase of left ventricular diameters, both in systole (from $3.4 \pm 8 \mathrm{~cm}$ to $3.7 \pm 8 \mathrm{~cm}$; $P<0.05$ ) and diastole (from $4.2 \pm 8 \mathrm{~cm}$ to $4.7 \pm 9$ $\mathrm{cm} ; \mathrm{P}<0.05)$.

Finally the two parameters that reflect, in the present study, the rate of ventricular filling did change, indicating an improvement in ventricular filling as reflected by a reduction of the isovolumic relaxation time from $145 \pm 9.5 \mathrm{~ms}$ to $122 \pm 10.3 \mathrm{~ms}$; thus, the left ventricle needed less time to relax after propranolol. At the same time the diastolic closure rate of the mitral echogram was accelerated from $47 \pm 4 \mathrm{~mm} / \mathrm{s}$ to $76 \pm 8 \mathrm{~mm} / \mathrm{s}$, this change being statistically significant $(\mathbf{P}<0.001)$. 


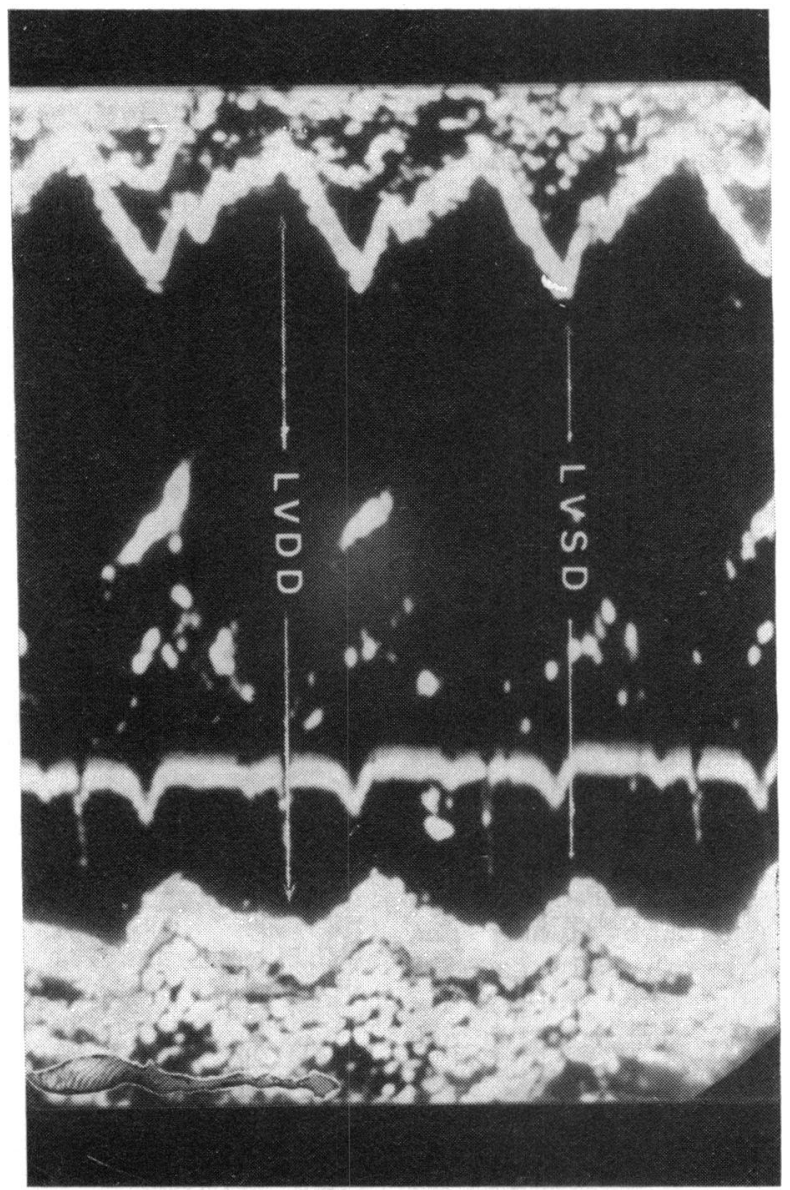

FIG. 4 Left ventricular diameters by echocardiography. Left ventricular diastolic diameter (LVDD) and left ventricular systolic diameter (LVSD).

No patient had any side effect caused by the administration of $5 \mathrm{mg}$ propranolol during the study. The blood pressure did not change significantly from the control state.

\section{Discussion}

Though propranolol has been the drug of choice in the medical treatment of HOCM for almost a decade (Flamm et al., 1968; Harrison et al., 1964), there is still some disagreement as to its place in the management. Some authors (Goodwin and Oakley, 1972) suggest that it should be given to all patients, seven those who are asymptomatic, while other suggest that it should be reserved only for those who have not responded to cardiac surgery (Rookmaker et al., 1971).
This controversy may very well be because of the lack of objective data at the bedside on which to judge the haemodynamic effects of propranolol.

Of patients with HOCM 14 per cent are asymptomatic or have symptoms that are difficult to assess (Hardarson et al., 1973). In this group of patients it is difficult or impossible to judge clinically the effects of propranolol. Such effects can be measured by haemodynamic studies (Kristinsson, 1971), but this method cannot be repeated serially. Therefore, non-invasive techniques, in the assessment of propranolol in HOCM, may have practical importance.

In a previous publication from this laboratory (Hubner et al., 1973), it was shown that the haemodynamic effects of oral propranolol ( $320 \mathrm{mg}$ daily) on a long-term basis could be assessed by non- 
invasive methods. In the present study a similar approach was taken to see if $5 \mathrm{mg}$ propranolol given intravenously would produce effects which could be measured by non-invasive methods.

The results of the present study are summarized in the Table.

The bradycardic effects of propranolol are well known and need no further comment. The LVETI is abnormally prolonged in HOCM, and is related to the outflow tract obstruction (Hardarson, 1974); it became shorter after intravenous propranolol. (From $428 \pm 33 \mathrm{~ms}$ to $419 \pm 37 \mathrm{~ms}$; $P<0.05$.)

Two explanations can be given for this effect. Because propranolol reduces left ventricular outflow tract obstruction (Kristinsson, 1971) and LVETI is related to it (Hardarson, 1974), it is possible that the shortening of LVETI encountered in the present study may reflect the amelioration of the outflow obstruction produced by propranolol. An alternative explanation is that the shortening of LVETI reflects the reduction of contractility produced by propranolol (Epstein and Braunwald, 1966), despite an improvement in ventricular filling.

The shortening of LVETI observed in the present study is in contrast to the prolongation of left ventricular ejection time reported by Hubner et al. (1973) in HOCM treated with daily doses of $320 \mathrm{mg}$ propranolol. In the latter situation the further prolongation of left ventricular ejection time was related to an increase in stroke volume following greater ventricular filling.

The suggestion that ventricular compliance may be improved after propranolol is supported by the shortening of isovolumetric relaxation time (from $145 \pm 0.5 \mathrm{~ms}$, to $122 \pm 10.3 \mathrm{~ms}$ ), and the acceleration of the diastolic closure rate of the mitral echogram $(47 \pm 4 \mathrm{~mm} / \mathrm{s}$, to $76 \pm 8 \mathrm{~mm} / \mathrm{s})$.

Isovolumetric relaxation time is related directly to the rate of ventricular relaxation and aortic pressure, and inversely to heart rate (Benchimol and Ellis, 1967). With the slowing of heart rate produced by propranolol, an increase in isovolumetric relaxation time might have been expected. As only a small, insignificant, change in blood pressure was found, shortening of isovolumetric relaxation time may reflect a better relaxation of the left ventricle. This is further supported by the concomitant acceleration of the diastolic closure rate of the mitral valve, for diastolic closure rate is related to the rate of ventricular filling (Wolfson, Ahmad, and Kerber, 1973; Layton et al., 1973).

Echocardiography is an accepted method of measuring left ventricular diameters (Pombo et al., 1971); therefore the increase in systolic and diastolic diameters induced by propranolol (Table)
TABLE Results

\begin{tabular}{lrlll}
\hline Case No. & $\begin{array}{l}\text { HR } \\
\text { Control }\end{array}$ & Propranolol & \multicolumn{2}{c}{ LVETI } \\
Control & Propranolol \\
\hline 1 & 73 & 66 & 404 & 409 \\
2 & 114 & 79 & 448 & 429 \\
3 & 94 & 80 & 411 & 418 \\
4 & 105 & 77 & 454 & 421 \\
5 & 55 & 51 & 481 & 476 \\
6 & 63 & 57 & 409 & 404 \\
7 & 72 & 61 & 440 & 435 \\
8 & 68 & - & 482 & - \\
9 & 95 & 73 & 404 & 402 \\
10 & 61 & 58 & 389 & 375 \\
11 & 66 & 66 & 495 & 489 \\
12 & 68 & - & 414 & - \\
13 & 65 & - & 417 & - \\
14 & 74 & 66 & 497 & 402 \\
15 & 90 & - & 415 & - \\
16 & 80 & 69 & 382 & 362 \\
17 & 104 & 69 & 431 & - \\
\hline Mean & 79 & 67 & 428 & 419 \\
SD & 18 & 9 & 33 & 37 \\
P value & & $<0.005$ & & $<0.05$ \\
\hline
\end{tabular}

\begin{tabular}{|c|c|c|c|}
\hline Parameters & Control $\pm S D$ & Propranolol & \\
\hline HR & \pm 18 & $67 \pm 9$ & $(\mathrm{P}<0.005)$ \\
\hline LVETI (ms) & $428 \pm 33$ & $419 \pm 37$ & $(P<0.05)$ \\
\hline IRT (ms) & $145 \pm 9 \cdot 5$ & $122 \pm 10 \cdot 3$ & $(P<0.01)$ \\
\hline $\operatorname{DCR}(\mathrm{mm} / \mathrm{s})$ & $47 \pm 4$ & $76 \pm 8$ & $(P<0.001)$ \\
\hline $\operatorname{LVSD}(\mathrm{cm})$ & $3 \cdot 4 \pm 8$ & $3 \cdot 7 \pm 8$ & $(P<0.05)$ \\
\hline $\operatorname{LVDD}(\mathrm{cm})$ & $4 \cdot 2 \pm 8$ & $4 \cdot 7 \pm 9$ & $(P<0.05)$ \\
\hline
\end{tabular}

HR: heart rate; LVETI: left ventricular ejection time index; IRT: isovolumic relaxation time; DCR: diastolic closure rate; LVSD: left ventricular systolic diameter; LVDD: left ventricular diastolic diameter.

can be interpreted as a real dilatation of the ventricle.

The combination of ventricular dilatation, shortening of isovolumetric relaxation time, and acceleration of the diastolic closure rate of the mitral valve, may thus very well represent an improvement of ventricular compliance.

This explanation is in agreement with other observations from acute studies with practolol in HOCM (Webb-Peploe et al., 1971), where the possibility of improved compliance was also suggested.

The resulting studies, therefore, indicate that non-invasive methods are capable of detecting haemodynamic changes produced by acute administration of propranolol, and that these changes suggest improved ventricular compliance. 


\section{References}

Benchimol, A., and Ellis, J. G. (1967). A study of the period of isovolumic relaxation in normal subjects and in patients with heart disease. American fournal of Cardiology, 19, 196.

Bentall, H. H., Cleland, W. P., Oakley, C. M., Shah, P. M., Steiner, R. E., and Goodwin, J. F. (1965). Surgical treatment and postoperative haemodynamic studies in hypertrophic obstructive cardiomyopathy. British Heart Fournal, 27, 585.

Braunwald, E., Morrow, A. G., Cornell, W. P., Aygen, M. M., and Hilbish, T. F. (1960). Idiopathic hypertrophic subaortic stenosis. Clinical, haemodynamic and angiographic manifestations. American fournal of Medicine, 29, 924.

Brock, R. (1957). Functional obstruction of the left ventricle (acquired aortic subvalar stenosis). Guy's Hospital Reports, 106, 221.

Cohen, L. S., and Braunwald, E. (1967). Amelioration of angina pectoris in idiopathic hypertrophic subaortic stenosis with beta-adrenergic blockade. Circulation, 35, 587.

Cooley, D. A., Bloodwell, R. D., Hallman, G. L., LaSorte, A. F., Leachman, R. D., and Chapman, D. W. (1967). Surgical treatment of muscular subaortic stenosis. Circulation, 35, Suppl. I, 124.

Edler, I. (1967). Ultrasoundcardiography in mitral valve stenosis. American fournal of Cardiology, 19, 18.

Epstein, S. E., and Braunwald, E. (1966). Beta-adrenergic receptor blocking drugs. Mechanisms of action and clinical applications. New England fournal of Medicine, 275, 1106.

Flamm, M. D., Harrison, D. C., and Harcock, E. W. (1968). Muscular subaortic stenosis: prevention of outflow obstruction with propranolol. Circulation, 38, 846.

Goodwin, J. F., Hollman, A., Cleland, W. P., and Teare, D. (1960). Obstructive cardiomyopathy simulating aortic stenosis. British Heart fournal, 22, 403.

Goodwin, J. F., and Oakley, C. M. (1972). The cardiomyopathies. British Heart fournal, 34, 545.

Goodwin, J. F., Shah, P. M., Oakley, C. M., Cohen, J., Yipintsoi, T., and Pocock, W. (1964). The clinical pharmacology of hypertrophic obstructive cardiomyopathy. In Cardiomyopathies, p. 189. Ed. by G. E. W. Wolstenholme and M. O'Connor. Churchill, London.

Hardarson, T. (1974). Systolic time intervals in ischaemic heart disease, congestive cardiomyopathy and hypertrophic obstructive cardiomyopathy. PhD Thesis, University of London.

Hardarson, T., de la Calzada, C. S., Curiel, R., and Goodwin, J. F. (1973). Prognosis and mortality of hypertrophic obstructive cardiomyopathy. Lancet, 2, 1462.
Harrison, D. C., Braunwald, E., Glick, G., Mason, D. T., Chidsay, C. A., and Ross, J. (1964). Effects of betaadrenergic blockade on the circulation, with particular reference to observations in patients with hypertrophic subaortic stenosis. Circulation, 29, 84 .

Hubner, P. J. B., Ziady, G. M., Lane, G. K., Hardarson, T., Scales, B., Oakley, C. M., and Goodwin, J. F. (1973). Double blind trial of propranolol and practolol in hypertrophic cardiomyopathy. British Heart fournal, 35, 1116.

Kristinsson, A. (1971). Beta-adrenergic blockade in hypertrophic obstructive cardiomyopathy with emphasis on exercise studies. In Hypertrophic Obstructive Cardiomyopathy, p. 113. Ed. by G. E. W. Wolstenholme and M. O'Connor. Churchill, London.

Layton, C., Gent, G., Pridie, R., McDonald, A., and Brigden, W. (1973). Diastolic closure rate of normal mitral valve. British Heart fourral, 35, 1066.

Pombo, J. F., Troy, B. L., and Russell, R. O. (1971). Left ventricular volumes and ejection fraction by echocardiography. Circulation, 43, 480.

Popp, R. L., Aderlman, E. L., Brown, O. R., and Harrison, D. C. (1973). Sources of error in calculation of left ventricular volumes by echography. American fournal of Cardiology, 31, 152.

Rookmaker, W. A., Nieveen, J., Kruizinga, K., and Blickman, J. R. (1971). Beta-adrenergic blockade in the treatment of left-sided hypertrophic obstructive cardiomyopathy. Acta Medica Scandinavica, 189, 427.

Webb-Peploe, M. M., Croxson, R. S., Oakley, C. M., and Goodwin, J. F. (1971). Cardioselective beta-adrenergic blockade in hypertrophic obstructive cardiomyopathy. Postgraduate Medical fournal, 47, Suppl. Jan, 93.

Weissler, A. M., Harris, W. S., and Schoenfeld, C. D. (1968). Systolic time intervals in heart failure in man. Circulation, 37, 149.

Wolfson, P., Ahmad, M., and Kerber, R. E. (1973). Relationship of echocardiographic mitral valve early diastolic closure velocity and left atrial pressure. Circulation, 48, Suppl. IV, 232.

Requests for reprints to Professor J. F. Goodwin, Division of Cardiovascular Diseases (Clinical Cardiology), Department of Medicine, Royal Postgraduate Medical School, Hammersmith Hospital, London W12 0HS. 